\title{
Quality control of the traditional herbs and herbal products: a review
}

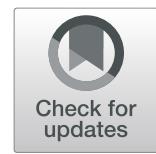

\author{
Amruta Balekundri and Vinodhkumar Mannur
}

\begin{abstract}
Background: Herbal medicinal material and product need is increasing, and with this increase in the need, it is very much an essential requirement to maintain the quality of them.

Main body: The quality of the herbals is altered by various physical, chemical, and geographical aspects which contribute to the quality of these materials. Apart from that, adulteration is also an increasing concern when it comes to herbal material quality. Various chemical and phytochemical test, analytical techniques, and hyphenated analytical techniques are used for determining the quality aspects of the herbal materials in the herbal pharmaceuticals.

Conclusion: These techniques can be used as quality control tool in assessing the quality of herbal materials and herbal pharmaceuticals.
\end{abstract}

Keywords: Quality, Herbals, Analytical technique

\section{Background}

Quality is of prime concern to human beings in all aspects of life. When it comes to the quality of the pharmaceuticals which are consumed by humans, it is of utmost important as they are used for the wellbeing of the human kind. There are stringent guidelines and regulation for the quality control of the synthetically synthesized chemical pharmaceuticals. They have to undergo various series tests and quality control checks before being marketed and consumed by the patients and consumers. Due to this stringency in the regulations, the quality of the synthetically manufactured pharmaceuticals is maintained up to the mark which assures both safety and efficacy of the pharmaceutical products.

Herbal medicinal products are the ones which are obtained from the plant resources for the treatment and wellbeing of mankind. It is very much essential that even the quality of the herbal medicines is being controlled as that of the chemically synthesized medicines. But unfortunately the regulation norms for the herbals are not as

\footnotetext{
* Correspondence: amrutaabc11@gmail.com

Department of Pharmaceutical Quality Assurance, KLE College of Pharmacy, JNMC Campus Nehru Nagar, Belagavi, Karnataka 590010, India
}

strict when compared to the synthetic drugs. This is leading to a decrease in the quality standards of the herbal products by intentional and sometimes unintentional adulteration, spurious drugs, substitution of drugs, and many other ways which are prone to decreasing the quality of the herbal materials which are marketed and consumed for the healthy survival. But instead of this, it is leading to hazardous effects on the health of the consumers. So it is very much required to control the quality standards of the herbal drugs and products for the betterment of the mankind.

Standardization and the phytochemicals investigation are carried out; apart from these, there are various quality control tools which are used to assure the quality aspects of the herbals. Both qualitative and quantitative measures are required for the quality assurance of them. Different techniques like UV (ultraviolet) and IR (infrared) are mostly used for the qualitative aspects whereas HP-TLC (high-performance thin-layer chromatography), HP-LC (high-pressure/performance liquid chromatography), SFC (supercritical fluid chromatography), thermal analysis, ICP-MS (inductively coupled plasma-mass spectroscopy), LC-MS (liquid chromatography-mass spectroscopy), and
Springer Open (c) The Author(s). 2020 Open Access This article is licensed under a Creative Commons Attribution 4.0 International License, which permits use, sharing, adaptation, distribution and reproduction in any medium or format, as long as you give appropriate credit to the original author(s) and the source, provide a link to the Creative Commons licence, and indicate if changes were made. The images or other third party material in this article are included in the article's Creative Commons licence, unless indicated otherwise in a credit line to the material. If material is not included in the article's Creative Commons licence and your intended use is not permitted by statutory regulation or exceeds the permitted use, you will need to obtain permission directly from the copyright holder. To view a copy of this licence, visit http://creativecommons.org/licenses/by/4.0/. 
GC-MS (gas chromatography-mass spectroscopy) are used for the quantitative estimation of the herbal products for quality control assessment.

As there is a growing demand for herbal pharmaceuticals, there is a need to assure their quality. Almost about $80 \%$ of the population is depending on the herbs for the treatment, cure, and prevention. So the different tools and techniques must be implied to verify and insure the required quality to be incorporated into the herbal material and products. There must be guidelines and/or norms framed for carrying out the quality control testing of the herbs which are almost or equally strict as that of the synthetic pharmaceuticals. This will help to maintain the quality standards of the herbal pharmaceutical which is the challenging task and need of the hour in the pharmaceutical research and quality assurance.

\section{Main text}

\section{Standardization of medicinal herbs and products}

The phytochemical constituents present in herbal formulations vary with the variation in the climate, composition, and components of the soil and the region where grown; all these parameters contribute as the obstruction in the process of standardization. The gradual increase in the adulteration and also substitution of herbal drugs are due to the rise in deforestation area. This adulteration and substitution harms the safety and efficacy of the drug.

Adulteration, substitution, and lack of skilled personnel are the main reasons for unavailability of genuine herbal drugs. By use of advanced quality control technique and suitable standards, there is need to assure the quality of the medicinal herbal products. Identification, quality, and purity of herbs and herbal product confirmation are done by the means of standardization. Preliminary identification, physical properties, chemical properties, and biological properties together contribute to the purity of herbs. This purity defines the freshness as well as the quality of the herbal products.

Quality control of herbals is of greater importance for preservation of quality of the natural herbs and products. When the quality control aspect has identification of substance, adulterants, and substitutes; purity of material; and assay of active chemical constituent of greater importance of the particular herb, then they are called as pharmacopeial aspects of quality control. The process where the qualitative and quantitative values of herbs are measured against the prescribed or set standards and parameters is standardization.

Based on the different important evaluation parameters like organoleptic properties, ash values, moisture content, microbial contamination, and chromatographic and spectroscopic evaluations, the WHO for the standardization of herbal drugs with current and future trends has set guidelines for standardization methods and procedures [1-3].
Modern analytical techniques for the analysis of the herbal drugs are very much essential for global acceptance of Ayurveda and traditional herbs. Scientific basics of quality of the traditional herbs and ayurvedic products can be gained by complete and accurate pharmacognostical assessment. For the authentication and standardization the organoleptic tests, physicochemical studies and pharmacognostical scheme are at most needed [4]. For the prevention of the genuine herbal materials getting adulterated, the data reported from microscopic and macroscopic studies can serve as an added advantage for identification of adulterants and authentication of genuine herbs. Moreover for confirmation of parameters for the standardization and the identification of the secondary metabolites (alkaloids, tannins, glycosides, saponins, and flavonoids) will act as a useful tool [5-7].

In accordance with the process for formulation of standard setting of herbal drugs in the pharmacopeia and other standard texts, the microscopic investigation(qualitative and quantitative), macroscopic (shape and markings), identifications (adulterants and genuine drug), physicochemical parameters (moisture content, acid insoluble ash, water soluble ash), pharmacognostical scheme, and other parameters reported for the first time can play a role of significant tool for authentication of herbs in future studies [8-10].

\section{Thermal analysis for the characterization of herbs and herbal products}

In verification of quality, purity and integrity of the herbals special techniques and strategies are applied due to the complex nature of the components of the herbals. Thermal stability of the samples, determination of the mass and enthalpy variation, high sensitivity, reproducibility and rapid response to the variation of results are the qualities of the thermal techniques like thermo gravimetric analysis (TGA) and differential thermal analysis (DTA) [11].

For the characterization of herbal extract and herbal drug products, thermal analysis can be used as an effective tool. Control of raw material quality, determination of purity, determination of thermal stability, compatibility of stability of substances, qualitative and quantitative drug analysis are important applications of the thermal methods. The reaction order $(n)$, activation energy $(E a)$, frequency factor $(A)$, and degradation constant are the different parameters used in the characterization of the herbal extracts which can be evaluated and studied with the thermal techniques (like TGA and DTA). Further, the absolute water content, crystal water content, and thermal degradation can also be assessed by these thermal techniques [12, 13].

In thermal analysis, time and temperature functions are used as defining parameters. The temperature ranges from 25 to $1000{ }^{\circ} \mathrm{C}$ are used in the thermal analytical 
procedures. Mass Signals are obtained during the heating processes of the analysis which reveal about the mass loss (mass lost in the thermal degradation process) in different defining steps (endothermic and exothermic) [14].

Determination of the variation in both iso-thermal and non-iso-thermal conditions contribute for the stability of aspects of the substances under the thermal analysis.

Interaction between the components of the drugs is studied by the interaction between the excipients and the active pharmaceutical ingredients (API) as the compatibility criteria by the means of TG, DTG (differential thermo gravimetric analysis), and differential scanning calorimetry (DSC) thermal analytical techniques. For the thermal behavior of polymers, TG and DSC are used as an evaluating tool for polymer and drug compatibility as pre-formulation study of the new formulations to be established [15].

The drugs are to be disposed after the thermal degradation is taken place, so prior to this disposal process, studies are conducted where in the behavioral patterns of the drug after and during the degradation process are studies so that the level of toxicity nature of the drugs and drug product can be analyzed which can help in accessing the process to be selected for disposing of such degraded drugs and drug product as the preventive measure to reduce the potential hazard caused by the disposed degraded substances to the environment.

Arrhenius equation is of utmost importance for calculations to be carried out from the data collected from thermal analysis,

$$
\begin{aligned}
& \mathrm{Ln} K=\ln A-\mathrm{Ea} / \mathrm{RT}[\mathrm{OR}] k(T)=\mathrm{A} \cdot \mathrm{e}^{-\mathrm{Ea} / \mathrm{RT}} \\
& \text { where } A=\text { frequency factor, } \\
& K=\text { rate constant, } \\
& \mathrm{Ea}=\text { activation energy, and } \\
& R=\text { gas constant }\left(8.314 \mathrm{Jk}^{-1} \mathrm{~mol}^{-1}\right)
\end{aligned}
$$

When the value of the temperature component increases in the equation, the value of the exponential part reduces and in turn there is an increase in the value of $k$.

The minimum energy required for the thermal process is called activation energy. As the particle size of the sample plant material decreases there is increase in the surface area and instability of sample, so this increase in the surface area leads to the lowering of the activation energy for the thermal process. So as the particle size decreases the value of activation energy also decreases (Table 1) [12].

\section{HP-TLC analytical technique for the herbal botanical formulation quality control}

To establish the pharmacopeial standards of various herbal ayurvedic, Siddha as well as other medicinal herb formulations by the means of HPTLC fingerprinting profile as a major quality control aspect. By this, HPTLC means phytochemical components of the formulations can be disclosed and efficacy, safety, and quality can be assured $[19,20]$.

The efficiency and safety of the final herbal medicine is based on the quality and the profile of the components of the formulations. Difficulty or barriers in the way of quality control testing of the herbal formulations are due to the complexity and variation in the chemical components of herbal-based formulations or compositions. Modern analytical techniques like HPTLC are used to bypass the problems which are covering the way of quality control aspects of herbal formulations [21-23].

With the growing advances in science, HPTLC is becoming one of the prime options for the quality control of the herbal plants. HPTLC technique is used simultaneously in comparison with both reference and samples and can work as quality control tool apart from identification. Based on the recommendation of monographs,

Table 1 Non iso-thermal/dynamic kinetic study and iso-thermal study in thermal analysis [16-18]

Non iso-thermal/dynamic kinetic study
To obtain the thermo gravimetric curve, the heating rate is variable in
non iso-thermal process/study.

When heating rate of the non iso-thermal process is increased the thermal curves as well as the fractional conversion move into the high temperature zones. The initial gasification temperature and the total gasification temperature when increasing the time taken for the gasification process reduces.

The Ozawa dynamic method is applied for studying the non iso-thermal process in thermal analysis. In this Ozawa dynamic model, different heating rates $(\beta)^{\circ} \mathrm{C} \mathrm{min}^{-1}$ and the dynamic air atmosphere

$\left(50 \mathrm{~mL} \mathrm{~min}{ }^{-1}\right)$ is maintained and the sample was analyzed.

Activation energy is obtained by plotting $\log \beta$ vs $1 / T$ further kinetic parameters frequency factor and reaction order can be obtained by implying Arrhenius equation $k(T)=A \cdot e^{-E a / R T}$

\section{Iso-thermal study}

In iso-thermal study/process, the heating rate is always kept same whereas the temperature of isotherms is varied and the estimation of decomposition time is carried out for the selected range.

In iso-thermal process when temperature is increased, the gasification processes gets accelerated. The time which is required to reach the peak conversion is reduced as the gasification rate and gasification temperature is increased.

In the iso-thermal study, the sample is heated with the heating rate $(\beta)$ of $20^{\circ} \mathrm{C} \mathrm{min}^{-1}$ from room temperature till it reduces to $T_{\text {isotherm }}-10^{\circ} \mathrm{C}$; further, the sample is heated with heating rate $(\beta)$ of $2{ }^{\circ} \mathrm{C} \mathrm{min}{ }^{-1}$ from $\mathrm{T}_{\text {isotherm }}-10^{\circ} \mathrm{C}$ to $T_{\text {isotherm, }}$ and finally the temperature is kept constant until the sample mass is reduced by at least $10 \%$ of the initial sample mass.

Activation energy is obtained by plotting In $T$ V $1 / T$ at constant conversion level and calculations are carried out using Arrhenius equation $k(T)=A \cdot e^{-E a / R T}$ and reaction order and frequency factors are calculated. 
various tests are carried out for the identification and quality control of the herbal plants and formulations. Peak profiles and their intensities are obtained from the HPTLC fingerprint images which give both qualitative and quantitative results in comparison with reference standards. Marker compound identification, percentage of purity, and minimum content information is also obtained by this technique of HPTLC [24-27].

For preliminary analysis for identification of adulteration and substitutes, pharmacognostic and phytochemical test and physicochemical properties act as the quantitative tests. For quantitative estimation of the phyto-constituents, HP-TLC technique is widely used due to the accuracy and simplicity of the technique. When samples are collected which differ in the area where they are grown and the climatic conditions, they are evaluated for different properties and phytochemical components. Apart from chromatograms and fingerprints digital images, visual detection is also possible even when the amount of samples and standards are prepared in microliter concentration. Simultaneous application of samples and standards on the same HP-TLC plate is possible and due to this property, it becomes easier during the comparative studies of herbal drugs and formulations [28-31].

\section{HP-LC analytical technique for analysis of botanical formulations for the quality control}

In the discovery domain, the identification (quantitative and qualitative) of active compounds from the herbal extract is the most difficult and challenging task. In modern discovery, the processes like isolation with preparative bio-activity do not match the pace as they are slow and tedious, whereas modern systems prefer for easy, accurate, and fast processes to be utilized. Traditional techniques, which use multiple isolations, can lead to decrease or completely vanishing of the activity of the active compound. So to overcome the drawbacks, profiling of compounds with HPLC analytical technique is done in modern discovery to identify the multiple compounds accurately due to versatility of the analytical technique [32-34].

For the quality assurance, herbs and traditional medicinal products obtained from the extract of plants can be estimated for the chemical components with HPLC technique. In the identification of chemical phyto-constituents in herbal medicine products, the standardization technique with the marker profile is of greater benefit as the quantifications of the multiple constituents from the herbal medicinal formulations have issues related to safety and efficacy of the active essentials.

Separation of the components from traditional polyherbal medicinal formulations HPLC serves as one of the convincing analytical technique as it has being gaining importance for qualification, quantification, and authentication aspects in the quality control of herbs.

Further harvesting season, drying techniques, plant origin, presence of heavy metals, and microbial contents are the major reasons which vary the quality of the herbs and come in the way of quality control of herbs [35-37].

In the estimation of presence of active chemical and biological markers in the complex traditional herbal products, HPLC can be used as a beneficial tool for standardization with both quantitative and qualitative estimation. For the analysis of the thermo-liable substance present in the traditional herbal formulations, one of the prime options of analysis is HPLC technique with advancement of isocratic and gradient elution. Analysis of poly-component medicinal herbal products is also possible as well as effective with RP-HPLC (reverse phase-high-performance liquid chromatography). The technique of HPLC and RP-HPLC serves high reproducibility and ease of automation in the identification of multiple constituents of botanical preparations.

The liquid-liquid partitioning, solid-extraction, preparative liquid chromatography, and thin-layer chromatographic fractionation are the sampling techniques used to reduce the complexity of the matrix effect. Due to the complexity of the matrix the co-elution of the peaks of the multi-components of the herbal marker compound takes place during the HPLC analysis process of that particular compound under analysis [38].

\section{Supercritical fluid chromatography (SFC) as a tool for quality control of herbs}

The growing hazardous effect of the synthetic chemicals and organic solvents on the environment has developed need for the focus towards the green chemistry principles with increase in number of methods and processes which comply with the same. To acquire the principle analytes from the compounds even when different matrices are being used, supercritical fluid chromatography technique is used as an alternative for conventional organic solvent methods (like HPLC) [39].

In supercritical fluid chromatography method, compressed carbon dioxide $\left(\mathrm{CO}_{2}\right)$ with small part of organic solvents (like methanol) are together used as the mobile phase, where major part is of carbon dioxide and minor is organic solvent; due to this ratio, the supercritical fluid chromatography (SFC) method is named as an alternative chromatography.

SFC method is an eco-friendly method as it utilizes very less quantity of organic solvents and the low viscosity of mobile phase as the pressure drop is less when compared with liquid chromatographic techniques [40]. The organic solvents being used are to be stored properly with proper precautions as they are highly 
flammable in nature and hence utmost care must be taken for prevention of dangerous accidents causing fire and explosions. The high purchase price and disposal of organic also adds up to the disadvantage of the organic solvents [41].

Lipid, flavonoid, phenolic, alkaloids, saponins, carbohydrates, and analysis of wide variety of analytes can be carried out with the SFC technique. The fat-soluble vitamin analysis is gaining more importance.

Fast analysis in comparison with HPLC and GC technique SFC analysis uses significant shorter period of time and low amount of solvents and is eco-friendly which are the most important characteristics of the SFC technique. A broad multi-residue method can be carried out with the SFC technique as it analyses both polar and non-polar compounds with very high sensitivity. In the analytical SFC method, development has rapid equilibrium of volume as well as enhanced hydrophobic component (molecule) elutions. As water is absent in the system, this serves as an advantage for the SFC technique for the residues from ionization point.

SFC is also been noted as an unconventional method of sample preparation. It also finds application in large scale industries due to selective techniques and environment-friendly method. The integrity and quality of the analytical material is maintained prior to analysis due to absence of oxygen (no oxidation process), absence of light (no photolysis), and low temperature (no temperature dependent degradation) in the working environment of the SFC technique which also adds up to the advantages [42, 43].

\section{ICP-MS (inductively coupled plasma-mass spectroscopy)}

Elemental composition present in medicinal plants play crucial role in the biological system of living organisms the medicinal herbs can serve as an essential part in providing trace elements to humans in their diet. Medicinal plants during the process of cultivation get easily contaminated and therefore there must be well-defined limits of elemental composition decided for medicinal plants. The ability of element accumulation of plant and the geochemical nature of the soil are responsible for the level of presence of the elements in the medicinal plants. These medicinal plants are the connecting link between the living beings and trace elements. Natural origin of the medicinal herbals cannot assure the quality and safety as the quality dilutions take place due to industrialization, fertilizer, agricultural pesticides, pollutants, storage, and marketing process.

Ionic and non-ionic are the two forms in which the trace elements are available in plants. And these ionic and non-ionic forms are responsible for toxicity and level of bioavailability in living organisms. Chromium $(\mathrm{Cr})$, copper $(\mathrm{Cu})$, cobalt $(\mathrm{Co})$, ferrous $(\mathrm{Fe})$, and zinc
$(\mathrm{Zn})$ are the metals which when consumed in excess amounts lead to toxicity, whereas cadmium (Cd), lead $(\mathrm{Pb})$, and mercury $(\mathrm{Hg})$ are toxic elements even when consumed in low concentrations [44].

The elemental content associated with active chemical compound of the medicinal plant adds up both benefits and hazardous effects to the herbal product. The concentration of elemental content differs with the different geographical variation, and its most influencing factors are rainfall, type of soil and its $\mathrm{pH}$, and temperature. So the environmental geographical condition in which the medicinal herbs are grown plays a crucial role and is to be taken in consideration. ICP-MS (inductively coupled plasma-mass spectroscopy) and PIXE (partial induced Xray emission) are the methods being used for analytical and chemo-metric studies on herbs. These methods are useful to gain information about the relation between the medicinal plant elemental content and their effect on particular disease treatment [45].

For quality and safety of the herbal products, heavy metal testing is of the crucial concern. Elemental specificity, multi-isotope detection, high sensitivity, dynamic range, and possibility of extremely low detection limit are the advances provided by the ICP-MS analytical technique used for trace and ultra-trace element concentration detections [46].

Medicinal plants that undergo the elemental content analysis can be used as an alternative over the synthetically fortified drugs when we get a clear picture of the elemental composition of the medicinal herbs; hence, this medicinal herb can be used to overcome the trace metal deficiencies as well as no side effect of the chemically metal fortified synthetic products [47].

Disorders related to brain, digestive, kidney, liver, pancreas, reproductive system, and central nervous systems are caused when the elemental components go on accumulating in the living human body. Further, this can lead to various cancer cells developing if the exposure is high and repetitive. So it is very much required to analyze the limit of elemental content and composition in the medicinal herbal products [48].

\section{LC-MS for the quality control of botanical herbs}

When HPLC method is used individually without other method in combination, it has certain drawbacks in the raw material extract in complex matrix analysis where prior treatment for the API concentration and purification is needed for the process to be simplified and give better results. This drawback is overcome by using the mass spectroscopy (MS)-coupled HPLC technique that is LC-MS (liquid chromatography-mass spectroscopy), in which the technique highly improves the sensitivity of detection. For the method simplification of LC-MS-ion trap mass spectroscopy (Ion trap LC-MS), quadrapole 
time of flight high-resolution mass spectroscopy (QTOF HRMS) and triple-quadrapole mass spectroscopy (TQ LC-MS) are the different technique which can be coupled with the HPLC analytical method [49].

Structure characterization, molecular mass, information of fragmentation, retention time, and broad range of detection and high separation of analytical compounds are the abilities of the LC-MS technique. Raw plant material extract and marketed product identification, quantification, and quality control of the herbs can be carried out with LC-MS combined technique [50].

Complete documentation of the data necessary for the online qualitative analysis of the herbal extract can be acquired by performing LC fingerprinting process. The hyphenated LC-MS technique is employed where the structure elucidation of chemical components of the herbal extract is not possible individually with the HPLC analytical method. Identification of chromatographic peaks and the comparison study online is possible by use of the LC-MS technique.

Further, the detection of the adulterants in the extracts and botanical products and phytochemical analysis of the herbs has become easier due to the advantageous LC-MS technique which is applied for the process. The separation process as well as the identification process of the various compounds which are structurally similar can be identified; this serves as one of the most superior qualitative tool among the various tools for the analysis of different herbs and the adulterants. With the advances of the LC-MS technique, the screening and characterization of the adulterants (unknown and known) which are novel analog can also be detected and identified by applying this technique in the quality control of the materials [51].

For the analysis of the complex traditional herbals with high resolution, efficiency and sensitivity which is used to gain accurate mass information are all present in the powerful tool for analysis which is UHPLC-Q-TOF/MS (ultra-high-performance liquid chromatogram coupled with electrospray ionization tandem quadrapole-time of flight/mass spectroscopy). For the potential analysis of components of the chemical markers, the multivariate statistical analysis which are basically dependent on the available chemical information which makes the identification of the components much simpler. This UHPLC is one of the advance types in the LC-MS analytical technique [52].

\section{GC-MS (gas chromatography-mass spectroscopy) in the quality control analysis of herbs}

GC-MS (gas chromatography-mass spectroscopy) is the analytical technique which is the combination of GC (gas chromatography) which separates the different components of the mixtures of the chemical compounds whereas the MS (mass spectroscopy) which analyses the components which are being separated by the GC. In case of the herbal product analysis, the extract can be analyzed for the principle component by the GC-MS technique. GC-MS can also be used in the pharmaceutical industries, cosmetic products, food industry, and environmental and forensic application for the analysis of the components of the compound basically the active pharmaceutical ingredients.

The most important analysis which is carried out by GC-MS is the analysis of the thermo-stable volatile compounds and the volatile derivatives. Qualitative and quantitative analysis of the volatile oil determination is carried out by the GC-MS technique; it is also possible to determine the multiple components of the compound and drug metabolites. LC-MS is comparatively more sensitive than the GC-MS but LC-MS cannot analyze the thermally stable volatile components whereas it is only able to analyze the thermally unstable non-volatile compounds.

Identification of components (qualitative), separation of components, and quantification of different compounds are both volatile and non-volatile in a single analysis. It is possible to carry out the simultaneous analysis of different compounds [53-55].

In the field of the forensic science the GC-MS technique pre-treatment process is being used which is extremely simple when compared to the conventional pre-treatment process that is less complex in nature; this process is called as headspace solid-phase microextraction (HS-SPME) and together with GC-MS it is said to be HS-SPME-GC/MS. Different detection techniques are used in coupling with the GC-MS techniques that are electron capture detection (ECD) and electron ionization (EI) with single quadrapole MS and/or triple quadrapole MS (MS-MS) [56, 57].

Matrix-matched calibration standards are used in the gas chromatography to compensate for the matrix effect in this technique and this is one of the simple most and cheap technique. The GC-MS/MS technique performance is affected by the extract purity which is under analysis and is injected to the system, as the biochemical range of the herbs is wide in range and the nature of the herb is also complicated.

The GC-MS technique is not suitable for the thermoliable compounds. In case of the non-volatile components, they must be derivatized and then the analysis must be carried out $[58,59]$.

\section{Comparison of HPLC, HP-TLC, and GC}

The comparison of chromatographic techniques is shown in Table 2. 
Table 2 Comparison of chromatographic techniques [60-62]

\begin{tabular}{llll}
\hline Parameters & HPLC & HP-TLC & GC \\
\hline Stationary phase & Column & Paper/glass & Liquid/solid \\
Mobile phase & Solvent mixture & Solvent mixtures & Pure inert gas \\
Sample & One at one run & Many at a single run & One at one run \\
Pressure & High & Open & Controlled pressure \\
System & Closed & System peaks and visual by bands & Closed \\
Results & System (peaks) & Moderate to high & System (peaks) \\
Resolution & High to very high & 1-30 min & High to very high \\
Time & 2-60 min & Constant & $2-60$ min \\
Temperature & Constant & & Increasing \\
\hline
\end{tabular}

\section{Conclusion}

In the case of the herbal products which are part of traditional medicine system, the novel formulations developed are required to be standardized for safety, efficacy, and potency. It is required that the various techniques are used for the quality control examination of the herbs, which can be regulated to gain the required quality products by setting proper norms. And this in turn will provide the safer use and effective treatment and required potency of the products which will benefit mankind and society by providing means of wellbeing.

\begin{abstract}
Abbreviations
A: Frequency factor; API: Active pharmaceutical ingredient; DSC: Differential scanning calorimetry; DTA: Differential thermal analysis; DTG: Differential thermo gravimetric analysis; Ea: Activation energy; ECD: Electron capture detection; GC-MS: Gas chromatography-mass spectroscopy; HP-LC: Highpressure/performance liquid chromatography; HP-TLC: High-performance thin-layer chromatography; HS-SPME: Headspace solid-phase micro extraction; ICP-MS: Inductively coupled plasma-mass spectroscopy; IR: Infrared; K: Rate constant; LC-MS: Liquid chromatography-mass spectroscopy; PIXE: Partial induced X-ray emission; Q-TOF HRMS: Quadrapole-time of flight high-resolution mass spectroscopy; $R$ : Gas constant $\left(8.314 \mathrm{Jk}^{-1} \mathrm{~mol}^{-1}\right)$; RPHPLC: Reverse phase-high-performance liquid chromatography;

SFC: Supercritical fluid chromatography; TA: Thermal analysis; TGA: Thermo gravimetric analysis; TQ LC-MS: Triple-quadrapole mass spectroscopy; UHPLCQ-TOF/MS: Ultra-high-performance liquid chromatogram coupled with electrospray ionization tandem quadrapole-time of flight/mass spectroscopy; UV: Ultraviolet; WHO: World Health Organization
\end{abstract}

\section{Acknowledgements}

The authors kindly acknowledge KLE College of Pharmacy for the support.

\section{Authors' contributions}

$A B$ has done data collection and major contributor in review manuscript writing. VM has designed the concept, corrections, and drafting of the manuscript. All the authors have read and approved the manuscript.

\section{Funding}

No funding was received.

\section{Availability of data and materials}

All data and materials are available upon request.

Ethics approval and consent to participate

Not applicable

\section{Consent for publication}

Not applicable

\section{Competing interests}

No competing interests to declare.

Received: 22 April 2020 Accepted: 31 August 2020

Published online: 05 October 2020

\section{References}

1. Kamble MA, Mane MR, Ingole AR, Dhabarde DM (2018) Standardization of some marketed herbal formulation used in diabetes. J Adv Res Pharmaceut Sci Pharmacol Interven 2(1):22-26

2. Nazim MD, Aslam M, Khatoon R, Asif M, Chaudhary SS (2018) Physicochemical standardization of Hansraj (Adiantum capillus-Veneris). J Drug Delivery Therapeut 8(6-s):195-203

3. Marchese A, Barbieri R, Coppo E, Orhan IE, Daglia M, Nabavi SF, Izadi M, Abdollahi M, Nabavi SM, Ajami M (2017) Antimicrobial activity of eugenol and essential oils containing eugenol: a mechanistic viewpoint. Crit Rev Microbiol 43(6):668-689. https://doi.org/10.1080/1040841X.2017.1295225

4. Deogade MS, Prasad KS (2019) Standardization of wild Krushnatulasi (Ocimum tenuiflorum Linn) Leaf. Int J Ayurvedic Med 10(1):52-61

5. Shaheen N, Imam S, Abidi S, Sultan RA, Azhar I, Mahmood ZA (2018) Comparative pharmacognostic evaluation and standardization of Capsicum annuum L. (red chili). IJPSR 9(7):1000-1005

6. Liu C, Guo DA, Liu L (2018) Quality transitivity and traceability system of herbal medicine products based on quality markers. Phytomedicine 44:247-257

7. Steinhoff B (2019) Quality of herbal medicinal products: State of the art of purity assessment. Phytomedicine 60:153003. https://doi.org/10.1016/j. phymed.2019.153003

8. Rashid S, Zafar M, Ahmad M, Lone FA, Shaheen S, Sultana, Shinwari MI (2018) Microscopic investigations and pharmacognostic techniques used for the standardization of herbal drug Nigella sativa L. Microsc Res Tech 81(12): $1443-1450$

9. Zhang J, Wider B, Shang H, Li X, Ernst E (2012) Quality of herbal medicines: challenges and solutions. Complement Ther Med 20(1-2):100-106. https:// doi.org/10.1016/j.ctim.2011.09.004

10. Fernandes FH, Salgado HR (2016) Gallic acid: review of the methods of determination and quantification. Crit Rev Anal Chem 46(3):257-265. https://doi.org/10.1080/10408347.2015.1095064

11. Guimarães GP, Santos RL, Brandão DO, de Oliveira Cartaxo-Furtado NA, de Medeiros Cavalcanti AL, Macedo RO (2018) Thermoanalytical characterization of herbal drugs from Poincianella pyramidalis in different particle sizes. J Therm Anal Calorim 131(1):661-670

12. Cuinica LG, Macêdo RO (2018) Thermoanalytical characterization of plant drug and extract of Urtica dioica L. and kinetic parameters analysis. J Therm Anal Calorim 133(1):591-602

13. Liu Y, Yang L, Ma C, Zhang Y (2019) Thermal behavior of sweet potato starch by non-isothermal thermogravimetric analysis. Materials 12(5):699

14. Malucelli LC, Massulo T, Magalhães WL, Stofella NC, Vasconcelos EC, Carvalho Filho MAS, Murakami FS (2018) Thermal and chemical characterization of Dicksonia sellowiana extract by means of thermal analysis. Rev Bras 28(5):626-630 
15. Toma CC, Tita B, Olah NK, Statti G (2018) Investigation of thermal behavior of Nigellae sativae semen from different types of extracts. Studia Universitatis Babes Bolyai Chemia 63(2)

16. Brandão DO, Guimarães GP, Santos RL, Júnior FJ, Silva KM, Souza FS, Macêdo RO (2016) Model analytical development for physical, chemical, and biological characterization of Momordica charantia vegetable drug. J Anal Methods Chem. https://doi.org/10.1155/2016/7528297

17. Alves R, Reis TV, Silva LC, Storpírtis S, Mercuri LP, Matos JD (2010) Thermal behavior and decomposition kinetics of rifampicin polymorphs under isothermal and non-isothermal conditions. Braz J Pharmaceut Sci 46(2):343351. https://doi.org/10.1590/S1984-82502010000200022

18. Correia LP, Procópio JV, Santana CP, Pinto MF, Moura EA, Santos AF, Macêdo RO (2015) Herbal medicine physical quality evaluation by thermal analysis using adapted Ozawa method. J Therm Anal Calorim 122(1):207214. https://doi.org/10.1007/s10973-015-4638-5

19. Neethu Kannan B, Gayathri Devi V, Anitha John LG, Natarajan M, Kanagarajan A (2019) Pharmacognostic evaluation and HPTLC fingerprinting of Pirantai Vatakam, a Siddha formulation. J Phytopharmacol 8(2):33-37

20. Do T, Santi I, Reich E (2019) A harmonized HPTLC method for identification of various caffeine containing herbal drugs, extracts, and products, and quantitative estimation of their caffeine content. J Liq Chromatogr Relat Technol 42(9-10):274-281

21. Bhurat MR, Sanghavi RS, Nagdev SA, Patil DP (2018) HPTLC pingerprinting and quantification of SHATAVARIN IV in extract and polyherbal formulations. World J Pharmaceut Res 7(10):442-451

22. Tomar V, Beuerle T, Sircar D (2019) A validated HPTLC method for the simultaneous quantifications of three phenolic acids and three withanolides from Withania somnifera plants and its herbal products. J Chromatogr B 1124:154-160

23. Chewchida S, Vongsak B (2019) Simultaneous HPTLC quantification of three caffeoylquinic acids in Pluchea indica leaves and their commercial products in Thailand. Rev Bras 29(2):177-181

24. Frommenwiler DA, Kim J, Yook CS, Tran TT, Cañigueral S, Reich E (2018) Comprehensive HPTLC fingerprinting for quality control of an herbal drugthe case of Angelica gigas root. Planta Med 84(06/07):465-474

25. Shawky E, El Newehy NM, Beltagy AM, Abd-Alhaseeb MM, Omran GA, Harraz FM (2018) Fingerprint profile and efficacy-associated markers of Nigella sativa oil for geographical origin determination using targeted and untargeted HPTLC-multivariate analysis. J Chromatogr B 1087:108-117

26. Pundarikakshudu K, Sharma AK, Bhatt CJ, Kanaki NS (2019) Development and validation of a high-performance thin-layer chromatographic (HPTLC) method for simultaneous quantification of Reserpine, Atropine, and Piperine in Sarpagandha Ghanvati, a classical ayurvedic preparation. J AOAC Int 102(4):1021-1026. https://doi.org/10.5740/jaoacint.18-0382

27. Abhimanyu KK, Ravindra CS, Avanapu RS (2017) A validated HPTLC method for the quantification of friedelin in Putranjiva roxburghii Wall extracts and in polyherbal formulations. Bull Faculty Pharm Cairo Univ 55(1):79-84. https:// doi.org/10.1016/j.bfopcu.2016.11.002

28. Mangal AK, Tewari D, Shantha TR, Bansal S, Mangal M (2018) Pharmacognostical standardization and HPTLC fingerprinting analysis of Crocus sativus L

29. Laila O, Murtaza I, Abdin MZ, Ahmad S, Khan MS (2019) Development and validation of a high-performance thin-layer chromatography based method for the quantification of trigonelline in fenugreek (Trigonella foenumgraecum) seeds. JPC J Planar Chromatography-ModernTLC 32(2):95-102. https://www.researchgate.net/deref/http\%3A\%2F\%2Fdx.doi.org\%2F1 $0.1556 \% 2 F 1006.2019 .32 .2 .3$

30. Tomar V, Beeurle T, Sircar D (2019) A validated HPTLC method for the simultaneous quantifications of three phenolic acids and three withanolides from Withania somnifera plants and its herbal products. J Chromatogr B. https://doi.org/10.1016/j.jchromb.2019.06.009

31. Alam P, Kamal YT, Alqasoumi SI, Foudah Al, Alqarni MH, Yusufoglu HS (2019) HPTLC method for simultaneous determination of ascorbic acid and gallic acid biomarker from freeze dry pomegranate juice and herbal formulation. Saudi Pharmaceut J 27(7):975-980. https://doi.org/10.1016/j. jsps.2019.07.006

32. Hamburger M (2019) HPLC-based activity profiling for pharmacologically and toxicologically relevant natural products-principles and recent examples. Pharm Biol 57(1):328-334

33. Hemdan A, Tawakol SM (2018) HPLC-UV chromatographic methods for detection and quantification of undeclared withdrawn synthetic medications in counterfeit herbal medicines with confirmation by HPLCPDA and mass spectrometry. Chromatographia 81(5):777-783

34. Walters NA, de Villiers A, Joubert E, de Beer D (2017) Improved HPLC method for rooibos phenolics targeting changes due to fermentation. J Food Compos Anal 55:20-29

35. Nag M, Kar A, Chanda J, Mukherjee PK (2019) RP-HPLC analysis of methanol extract of Viscum articulatum-a plant from Ayurveda. J Ayurveda Integrative Med. https://doi.org/10.1016/j.jaim.2018.02.135

36. Raclariu AC, Paltinean R, Vlase L, Labarre A, Manzanilla V, Ichim MC, de Boer H (2017) Comparative authentication of Hypericum perforatum herbal products using DNA metabarcoding, TLC and HPLC-MS. Sci Rep 7(1):1-12

37. Gitea D, Vicas S, Gitea MA, Nemeth S, Tit DM, Pasca, B.,\& lovan, C. (2018) HPLC screening of bioactives compounds and antioxidant capacity of different hypericum species. Rev Chim 69(2):305-309

38. Govindarajan $R$, Tejas V, Pushpangadan P (2019) High-performance liquid chromatography (HPLC) as a tool for standardization of complex herbal drugs. J AOAC Int 102(4):986-992

39. Sánchez-Camargo ADP, Parada-Alonso F, Ibáñez E, Cifuentes A (2019) Recent applications of on-line supercritical fluid extraction coupled to advanced analytical techniques for compounds extraction and identification. J Sep Sci 42(1):243-257

40. Liu TT, Cheong LZ, Man QQ, Zheng X, Zhang J, Song S (2019) Simultaneous profiling of vitamin D metabolites in serum by supercritical fluid chromatography-tandem mass spectrometry (SFC-MS/MS). J Chromatogr B 1120:16-23

41. Zhong Y (2019) Electronic nose for food sensory evaluation. In: Evaluation technologies for food quality. Woodhead Publishing, pp 7-22

42. Murcia-Morales M, Cutillas V, Fernández-Alba AR (2019) Supercritical fluid chromatography and gas chromatography coupled to tandem mass spectrometry for the analysis of pyrethroids in vegetable matrices: a comparative study. J Agric Food Chem 67(46):12626-12632

43. Huang Y, Wang T, Fillet M, Crommen J, Jiang Z (2019) Simultaneous determination of amino acids in different teas using supercritical fluid chromatography coupled with single quadrupole mass spectrometry. J Pharmaceut Anal 9(4):254-258

44. Varhan Oral E, Tokul-Ölmez Ö, Yener I, Firat M, Tunay Z, Terzioğlu P et a (2019) Trace elemental analysis of allium species by inductively coupled plasma-mass spectrometry (ICP-MS) with multivariate chemometrics. Anal Lett 52(2):320-336

45. Rao JC, Naidu BG, Sarita P, Srikanth S, Raju GN (2019) Elemental analysis of Pterocarpus santalinus by PIXE and ICP-MS: chemometric approach. J Radioanal Nucl Chem 322(1):129-137

46. Tokalıoğlu Ş, Dokan FK, Köprü S (2019) ICP-MS multi-element analysis for determining the origin by multivariate analysis of red pepper flakes from three different regions of Turkey. LWT 103:301-307

47. Kumar V, Singh S, Singh A, Subhose V, Prakash O (2019) Assessment of heavy metal ions, essential metal ions, and antioxidant properties of the most common herbal drugs in Indian ayurvedic hospital: for ensuring quality assurance of certain ayurvedic drugs. Biocatalysis Agric Biotechnol 18:101018

48. Gonçalves DA, de Souza ID, Rosa ACG, Melo ESP, Goncalves AMB, de Oliveira LCS, do Nascimento VA (2019) Multi-wavelength calibration: determination of trace toxic elements in medicine plants by ICP OES. Microchem J 146:381-386

49. Marchetti L, Pellati F, Graziosi R, Brighenti V, Pinetti D, Bertelli D (2019) Identification and determination of bioactive phenylpropanoid glycosides of Aloysia polystachya (Griseb. et Moldenke) by HPLC-MS. J Pharm Biomed Anal 166:364-370

50. Wu W, Jiao C, Li H, Ma Y, Jiao L, Liu S (2018) LC-MS based metabolic and metabonomic studies of Panax ginseng. Phytochem Anal 29(4):331-340

51. Nanjappan S, Paul D, Bolla L (2018) Assessing herb-drug interactions of herbal products with therapeutic agents for metabolic diseases: analytical and regulatory perspectives. Stud Nat Prod Chem 59:283-322

52. Zhou J, Cai H, Tu S, Duan Y, Pei K, Xu Y, Zhou Q (2018) Identification and analysis of compound profiles of sinisan based on 'individual herb, herbpair, herbal formula' before and after processing using UHPLC-Q-TOF/MS coupled with multiple statistical strategy. Molecules 23(12):3128

53. Zhang A, Sun H, Wang X (2018) Mass spectrometry-driven drug discovery for development of herbal medicine. Mass Spectrom Rev 37(3):307-320

54. Wei D, Chang X, Cao Y, Yan H, Shang E, Qian D, Duan JA (2019) GC-MS based metabolomics to evaluate three commercial products of Chrysanthemun mori. https://doi.org/10.20944/preprints201902.0116.v1 
55. Gomathi D, Kalaiselvi M, Ravikumar G, Devaki K, Uma C (2015) GC-MS analysis of bioactive compounds from the whole plant ethanolic extract of Evolvulus alsinoides (L.) L. J Food Sci Technol 52(2):1212-1217

56. Saito K, Kaneko S, Furuya Y, Asada Y, Ito R, Sugie KI, Yanagawa Y (2019) Confirmation of synthetic cannabinoids in herb and blood by HS-SPME-GC/ MS. Forensic Chem 13:100156

57. Huertas-Pérez JF, Ernest M, Badoud F (2019) Quantification of folpet and phthalimide in tea and herbal infusions by LC-high-resolution MS and GCMS/MS. Food Additives Contaminants Part A 36(1):109-119

58. Taha SM, Gadalla SA (2017) Development of an efficient method for multi residue analysis of 160 pesticides in herbal plant by ethyl acetate hexane mixture with direct injection to GC-MS/MS. Talanta 174:767-779

59. Rutkowska E, Łozowicka B, Kaczyński P (2018) Modification of multiresidue QuEChERS protocol to minimize matrix effect and improve recoveries for determination of pesticide residues in dried herbs followed by GC-MS/MS Food Anal Methods 11(3):709-724

60. Ram M, Abdin MZ, Khan MA, Jha P (2011) HPTLC fingerprint analysis: a quality control for authentication of herbal phytochemicals. In highperformance thin-layer chromatography (HPTLC). Springer, Berlin, Heidelberg, pp 105-116. https://doi.org/10.1007/978-3-642-14025-9_7

61. Sankar SS, Sundar S, De Britto AJ (2018) HPLC and HPTLC fingerprint profile of Elytraria imbricata (Vahl) Pers. Sciencia Acta Xaveriana 9(2):49-54

62. Abraham A, Samuel S, Mathew L (2018) Phytochemical analysis of Pathyashadangam kwath and its standardization by HPLC and HPTLC. J Ayurveda Integrative Med 11(2):153-158

\section{Publisher's Note}

Springer Nature remains neutral with regard to jurisdictional claims in published maps and institutional affiliations.

\section{Submit your manuscript to a SpringerOpen ${ }^{\circ}$ journal and benefit from:}

- Convenient online submission

- Rigorous peer review

- Open access: articles freely available online

High visibility within the field

- Retaining the copyright to your article

Submit your next manuscript at $\boldsymbol{\nabla}$ springeropen.com 